\title{
Recombinant human hepatocyte growth factor transfection alleviates hyperkinetic pulmonary artery hypertension in rabbit models
}

\author{
Wei Wang, MD, ${ }^{\mathrm{a}}$ Kai Liu, MD, ${ }^{\mathrm{b}}$ Fang Zhang, $\mathrm{MD},{ }^{\mathrm{c}}$ Guangqing Cao, MD, ${ }^{\mathrm{b}}$ Yiqian Zhang, MD, ${ }^{\mathrm{a}}$ \\ Ruifang Liu, MD, ${ }^{\mathrm{b}}$ and Shuming $\mathrm{Wu}, \mathrm{MD}^{\mathrm{b}}$
}

Objective: The study objective was to investigate the effect of recombinant human hepatocyte growth factor gene transfection via an endotracheal approach on hyperkinetic pulmonary artery hypertension rabbit models.

\begin{abstract}
Methods: The rabbits with established pulmonary artery hypertension were separated into a gene transfection group (rabbits treated with intratracheal instillation of human hepatocyte growth factor $2 \times 10^{9}$ plaque-forming units coded by replication-defective recombinant adenovirus), an empty vector group, and a control group. Two weeks after endotracheal gene transfection, immunohistochemistry examination and Western blot were used to detect the protein expression of human hepatocyte growth factor. The hemodynamic data were measured, and pulmonary angiography was performed to investigate the pulmonary collateral vessels. The vascular density in lung also was analyzed.
\end{abstract}

Results: Two weeks after gene transfection, human hepatocyte growth factor was expressed in the gene transfection group. The mean pulmonary artery pressure in the gene transfection group was lower than in the control and empty vector groups $(P<.05$ for both). The arteriolar density in the lung tissues of the gene transfection group was higher than in the other groups $(P<.05)$, which was confirmed by immunohistochemistry, double-labeling immunofluorescence, and pulmonary angiography.

Conclusions: Human hepatocyte growth factor was expressed in rabbit lung after gene transfection via an airway approach. Recombinant human hepatocyte growth factor transfection ameliorates the pulmonary artery hypertension induced by shunt flow by promoting angiogenesis in lung tissues. (J Thorac Cardiovasc Surg 2013;146:198-205)

Hyperkinetic pulmonary artery hypertension (PAH) is a common and problematic complication of left-to-right shunt congenital heart disease. It increases morbidity and mortality, and seriously affects the prognosis of the patient. ${ }^{1}$ The current therapies of PAH mainly focus on the dilation of pulmonary arteries, such as inhalation of nitric oxide and administration of bosentan or prostacyclin. Although palliation of PAH was obtained from surgical manipulation ${ }^{2}$ and pharmacotherapies prolonged the survival of patients with PAH, the long-term outcome was not favorable because of the obstructive remodeling of pulmonary arterioles and the decrease in the available pulmonary vascular bed. ${ }^{3}$

From the Department of Cardiothoracic Surgery, ${ }^{\text {a }}$ Affiliated Hospital of Xuzhou Medical College, Xuzhou, Jiangsu, China; Department of Cardiovascular Surgery, ${ }^{\text {b }}$ Qilu Hospital, Shandong University, Jinan, Shandong, China; and Department of Rheumatology, ${ }^{\mathrm{c}}$ Jiangsu Province Academy of Traditional Chinese Medicine, Nanjing, Jiangsu, China.

This work was supported by the National Natural Science Funding of China (No. 30571845), the Natural Science Foundation of Jingsu Province of China (Grant BK2007033), and the Technology Bureau of Xuzhou of China (Grant XM09B072). Disclosures: Authors have nothing to disclose with regard to commercial support.

W.W. and K.L. contributed equally to this work.

Received for publication May 30, 2012; revisions received Aug 7, 2012; accepted for publication Aug 23, 2012; available ahead of print Sept 24, 2012.

Address for reprints: Shuming Wu, MD, Department of Cardiovascular Surgery, Qilu Hospital of Shandong University, Jinan, Shandong 250012, China (E-mail: shumingwumd@126.com).

0022-5223/\$36.00

Copyright (c) 2013 by The American Association for Thoracic Surgery http://dx.doi.org/10.1016/j.jtcvs.2012.08.056
In recent years, gene-based angiogenesis therapy has gained interest in many research fields. Therapeutic angiogenesis reduces vascular resistance and improves perfusion of tissues. ${ }^{4,5}$ Hepatocyte growth factor (HGF) and its receptor are widely distributed in the cardiovascular system. This protein is characterized as a multifunctional growth factor with mitogenic, antiapoptotic activities in a variety of cells. ${ }^{6}$ As a highly efficient angiogenesis factor, exogenous HGF has been used in the treatment of ischemic diseases, such as limb ischemia or even ischemic heart disease, ${ }^{7,8}$ to promote neovascularization and improve perfusion of ischemic tissues.

HGF is involved in lung regeneration and protection in response to acute lung injury, and deficiency of endogenous HGF is a feature of PAH pathogenesis. ${ }^{9}$ Its angiogenic effect is more significant than that of vascular endothelial growth factor and basic fibroblast growth factor. In addition, unlike vascular endothelial growth factor and basic fibroblast growth factor, HGF neither increases the permeability of blood vessels nor promotes the overproliferation of vascular smooth muscle cells (SMCs) to aggravate the original artery stenosis. ${ }^{10,11}$ Thus, HGF is more suitable for the therapy of PAH. Previous studies have reported the angiogenic effect of recombinant human hepatocyte growth factor (rhHGF) gene transferring into the lung via a catheter in rat models. ${ }^{9,12}$ However, there is no report on the application of rhHGF coded by an adenovirus vector via the endotracheal pathway under hyperkinetic pulmonary hypertension 


Abbreviations and Acronyms
Ad-hHGF $=$ adenovirus coding with human
hepatocyte growth factor

induced by a left-to-right shunt. Therefore, we hypothesized that exogenous HGF supplementation via a tracheal route might ameliorate PAH induced by a systemic-pulmonary shunt. In the current study, established PAH rabbit models were administered rhHGF via an intratracheal route. The effects of rhHGF transfection on pulmonary arterial pressure and the collateral vessel construction in lung tissues were investigated. Moreover, the relationship between pulmonary angiogenesis and pulmonary artery pressure was analyzed to explore the feasibility of exogenous HGF administration in decreasing pulmonary artery pressure.

\section{MATERIALS AND METHODS Animal Model Preparation}

The study conformed to the Guide for the Care and Use of Laboratory Animals of National Research Council of China. The experiment was approved by the Animal Care Committee of the Xuzhou Medical College of China. The animals received humane care in compliance with the Guide for the Care and Use of Laboratory Animals of Jiangsu Province of China. One-month-old New Zealand male rabbits (weighing $540 \pm 24 \mathrm{~g}$ ) were supplied by the Laboratory Animal Center of Xuzhou Medical College. A systemic-pulmonary shunt was established with left common carotid artery and pulmonary trunk anastomosis. The pulmonary hypertension model was established after 3 months, and the methods were described in our previous report. ${ }^{13}$

\section{Preparation of Adenovirus Vectors}

Recombinant adenovirus (replication-defective human serum adenovirus type 5 with cytomegalovirus promoter) coding with human HGF (Ad-hHGF) and adenovirus without HGF gene (Ad-Null) were constructed by the Academy of Military Medical Sciences and donated by Academician Wu Zuze. The recombinant adenovirus was purified by cesium chloride gradient centrifugation and desalted using Dialysis Cassettes (Slide-A-Lyzer 10k; Pierce, Rockford, Ill). The final plaque-forming units (Pfu) of virus were determined by titration on 293 cells under an agar overlay (Low Gelling Temperature; Sigma-Aldrich, St Louis, Mo). The virus was stored at $-80^{\circ} \mathrm{C}$ and protected from light until use. The purity of Ad-hHGF and Ad-Null was 1.32 and 1.31, respectively. The efficacy and safety of AdhHGF have been proven by Ha and colleagues. ${ }^{14}$

\section{Experimental Groups}

The rabbits with established PAH $(n=36)$ were randomly separated into 3 groups: control group ( $\mathrm{C}$ group, intratracheal instillation of phosphatebuffered saline, $\mathrm{n}=12$ ), empty virus control group (E group, intratracheal instillation of Ad-Null $2 \times 10^{9} \mathrm{Pfu}, \mathrm{n}=12$ ), and Ad-hHGF treatment group (H group, intratracheal instillation of Ad-hHGF $2 \times 10^{9} \mathrm{Pfu}$ as previously described, ${ }^{15,16} \mathrm{n}=12$ ). Briefly, after sterilization of the skin, the trachea was approached via a thyrocricoid puncture, and $200 \mu \mathrm{L}$ of vehicle containing the Ad-hHGF $2 \times 10^{9} \mathrm{Pfu}$ or equivalent Ad-Null or phosphate-buffered saline was instilled into the trachea. Immediately before instillation, circumferential compression of the thorax was performed to achieve a forced exhalation. After endotracheal instillation followed by $20 \mathrm{~mL}$ of air, compression was released. This caused a forceful inspiration that facilitated the adenoviral dispersion to the distal air spaces. The infective titer had been determined through preliminary experiments, in which the group with $2 \times 10^{9}$ Pfu showed the largest improvement in the PAH models and with less mortality than in the groups with other different titers.

\section{Measurement of Hemodynamic Parameters}

Two weeks after Ad-hHGF transfection, animals were anesthetized with an intramuscular injection of ketamine $(2 \mathrm{mg} / \mathrm{kg})$ and midazolam $(1 \mathrm{mg} / \mathrm{kg})$, followed by an intravenous bolus of ketamine $(1 \mathrm{mg} / \mathrm{kg})$ through the ear vein. The animals were intubated and supported with a ventilator. A stable anesthesia was maintained with continuous intravenous infusion of fentanyl $\left(30 \mu \mathrm{g} \cdot \mathrm{kg}^{-1} \cdot \mathrm{h}^{-1}\right)$ and midazolam $\left(2 \mathrm{mg} \cdot \mathrm{kg}^{-1} \cdot \mathrm{h}^{-1}\right)$. A right thoracotomy was performed through the fourth intercostal space. A purse-string suture was made on the ascending aorta and the pulmonary trunk with 7-0 Prolene (Ethicon Inc, Somerville, NJ). A piezometric catheter $(4 \mathrm{~F})$ was inserted, and the hemodynamic parameters were monitored simultaneously with the MacLab/8s multifunction physiologic instrument (M8680, ADInstruments Pty Ltd, Bella Vista, Australia). Hemodynamic parameters were recorded, including systolic pulmonary artery pressure, diastolic pulmonary artery pressure, mean pulmonary artery pressure (mPAP), and mean systemic arterial pressure.

\section{Pulmonary Artery Angiography}

After hemodynamic parameters were measured, pulmonary angiography was performed with digital subtraction angiography (Innova 4100, GE Healthcare, Waukesha, Wis). Via a piezometric catheter, $5 \mathrm{~mL}$ of meglumine was injected into the pulmonary artery, which was used for pressure measurement, and the images were recorded. The morphology, distribution of pulmonary artery, and construction of collateral circulation were investigated. The meglumine filling time also was recorded and analyzed.

\section{Preparation of the Tissues}

The animals were euthanized with an overdose of $3 \%$ pentobarbital (90$120 \mathrm{mg} / \mathrm{kg}$ ) via an intravenous infusion after imaging the pulmonary artery. Lung samples $(1 \times 1 \times 1 \mathrm{~cm})$ were cut from the apex of the superior lobe of the right lung for Western blot analysis. The left lung inferior lobe was fixed by $10 \%$ formalin and routinely processed into paraffin sections of $5 \mu \mathrm{m}$ in depth.

The great vessels were separated from the heart, and the residual blood was blotted. The heart was separated into the right ventricle (RV) and left ventricle (LV) plus ventricular septum (LV+VS) according to the methods previously described. ${ }^{17}$ The RV weight index (LV/LV+VS) was calculated to evaluate the hypertrophy of RV. ${ }^{13,18}$

\section{Immunohistochemistry Examination}

Ten slices were randomly selected in each model to detect the target proteins. After the slices were deparaffinaged with dimethylbenzene, they were washed twice and then heat processed $\left(92^{\circ} \mathrm{C}-98^{\circ} \mathrm{C}\right)$ for $15 \mathrm{~min}-$ utes to recover the antigens. The slices were blocked with goat serum and incubated with mouse antihuman HGF monoclonal antibody (1:100, Santa 
Cruz Biotechnology Inc, Santa Cruz, Calif) or rat anti-VIII factor (1:150, Santa Cruz Biotechnology Inc) at $4^{\circ} \mathrm{C}$ overnight. Biotinylated second antibody was added for 30 minutes at $37^{\circ} \mathrm{C}$. Then the slides were incubated with avidin-biotin complex at $37^{\circ} \mathrm{C}$ for 30 minutes. DAB kit (ZhongShan Golden Bridge Biological Technology, Bejing, China) was used for chromogenic reaction, and the slices were counterstained with hematoxylin. Control sections were incubated with noninmmune mouse or rat immunoglobulin- $\mathrm{G}$ at a concentration of 1:500. The pathologist was blinded to the experiments. The hHGF levels were quantified by the Image Pro Plus 6.0 system (Media Cybernetics Inc, Rockville, Md). The pulmonary arterial density was determined as the average number of the VIII factor-positive stained arteries along terminal bronchiole per millimeter squared as previously described. ${ }^{19}$

\section{Double-Labeling Immunofluorescence}

Paraffin sections of lung tissues were treated with hydrogen peroxide and blocked with goat serum. After incubation with the mixed primary antibody (mixture of mouse anti- $\alpha$ smooth muscle actin [ZhongShan Golden Bridge Biological Technology] and rat anti-VIII factor), rhodaminelabeled goat antimouse secondary antibody and fluorescein isothiocyanate-labeled goat antirat secondary antibody were used to display the SMCs and vascular endothelial cells (VECs) in the lung vessels, respectively. All manipulations were kept away from light. Four fields of vision were selected randomly in each slice and photographed under highpower microscope. The positive signals and the intensity of the fluorescence were analyzed by the Image Pro Plus 6.0 system.

\section{Western Blot}

Protein was drawn from $20 \mathrm{mg}$ of lung tissues, and protein concentrations were determined by the Bio-Rad protein assay instrument (Bio-Rad Laboratories Inc, Hercules, Calif). Equal amounts of protein were dissolved in sodium dodecyl sulfate polyacrylamide gel electrophoresis sample buffer, separated in sodium dodecyl sulfate polyacrylamide gel electrophoresis, and transferred onto polyvinylidene fluoride membrane. The membranes were incubated with the primary antibodies (mouse antihHGF) overnight at $4{ }^{\circ} \mathrm{C}$ and incubated with secondary antibodies conjugated to horseradish peroxidase for 1 hour at room temperature with continuous shaking. Protein blots were detected using an enhanced chemiluminescence kit (Millipore Corp, Billerica, Mass) and exposed to x-ray film. The recognized bands were quantified by FluorChem 9900 (Alpha Innotech, Santa Clara, Calif), and glyceraldehyde phosphate dehydrogenase was used as an internal reference.

\section{Statistical Analysis}

Data are shown as mean \pm standard deviation. The Statistical Package for the Social Sciences version 13.0 (SPSS Inc, Chicago, Ill) for Windows was used for all statistical analysis. One-way analysis of variance with a post hoc test of the least significant difference was used for statistical analysis.

\section{RESULTS \\ Hemodynamic Changes}

No animals died or experienced respiratory and other complications after the treatments. Two weeks after gene transfection, the mPAP $(16.61 \pm 3.40 \mathrm{~mm} \mathrm{Hg})$ and the weight index of the RV $(0.25 \pm 0.09)$ in the $\mathrm{H}$ group were significantly lower than in the $C$ group $(33.65 \pm 4.12 \mathrm{~mm}$ $\mathrm{Hg}$ and $0.45 \pm 0.03$, respectively) or $\mathrm{E}$ group $(29.99 \pm 5.22 \mathrm{~mm} \mathrm{Hg}$ and $0.47 \pm 0.07$, respectively, Table 1). There were no significant differences in the mean systemic arterial pressure among the 3 groups.
TABLE 1. Hemodynamic measurement and weight index of right ventricle in experimental rabbits

\begin{tabular}{lccc}
\hline & $\begin{array}{c}\text { C group } \\
(\mathbf{n}=\mathbf{1 2})\end{array}$ & $\begin{array}{c}\text { E group } \\
(\mathbf{n}=\mathbf{1 2})\end{array}$ & $\begin{array}{c}\text { H group } \\
(\mathbf{n}=\mathbf{1 2})\end{array}$ \\
\hline $\mathrm{sPAP}(\mathrm{mm} \mathrm{Hg})$ & $33.65 \pm 4.12$ & $29.99 \pm 5.22$ & $16.61 \pm 3.40^{*}, \dagger$ \\
$\mathrm{dPAP}(\mathrm{mm} \mathrm{Hg})$ & $15.28 \pm 3.31$ & $17.04 \pm 2.93$ & $8.45 \pm 2.12^{*}, \dagger$ \\
$\mathrm{mPAP}(\mathrm{mm} \mathrm{Hg})$ & $21.14 \pm 2.61$ & $22.81 \pm 3.81$ & $12.47 \pm 3.49^{*}, \dagger$ \\
$\mathrm{mSAP}(\mathrm{mm} \mathrm{Hg})$ & $71.22 \pm 13.90$ & $69.39 \pm 16.23$ & $73.17 \pm 15.16$ \\
$\mathrm{RV} / \mathrm{BW}(\mathrm{g} / \mathrm{kg})$ & $0.92 \pm 0.21$ & $0.89 \pm 0.32$ & $0.52 \pm 0.42^{*}, \dagger$ \\
$\mathrm{LV} / \mathrm{BW}(\mathrm{g} / \mathrm{kg})$ & $2.61 \pm 0.82$ & $2.77 \pm 0.39$ & $2.81 \pm 0.24$ \\
$\mathrm{RV} /(\mathrm{LV}+\mathrm{VS})$ & $0.45 \pm 0.03$ & $0.47 \pm 0.07$ & $0.25 \pm 0.09^{*}, \dagger$ \\
Heart rate $($ beats/min $)$ & $247 \pm 51$ & $261 \pm 49$ & $274 \pm 38$
\end{tabular}

$S P A P$, Systolic pulmonary artery pressure; $d P A P$, diastolic pulmonary artery pressure; $m P A P$, mean pulmonary artery pressure; $m S A P$, mean systemic arterial pressure; $R V$, right ventricle; $B W$, body weight; $L V$, left ventricle; $V S$, ventricular septum. $* P<.05$ versus $C$ group. $\dagger P<.05$ versus $\mathrm{E}$ group.

Furthermore, the difference in mPAP between the $\mathrm{C}$ and E groups was not significant. After the gene transfection, there were no differences in heart rate among the groups.

\section{Expression of Human Hepatocyte Growth Factor Protein in Lung Tissues}

Two weeks after the treatment, immunohistochemistry examination showed no hHGF-positive signals in the lung tissues of the $\mathrm{C}$ and $\mathrm{E}$ groups. In the $\mathrm{H}$ group, diffuse immunostaining for hHGF was observed in the cytoplasm of VECs and alveolar epithelial cells. With the intratracheal approach, the hHGF expression in the tracheobronchial tree also was detected. Immunostaining examination showed a relatively high expression of hHGF in the bronchial ciliated cells and basal epithelial cells (Figure 1, A and $B$ ). To confirm that the expressed protein in lung tissues was hHGF, Western blot analysis was performed. Likewise, in addition to the glyceraldehyde phosphate dehydrogenase, the recognized band representing hHGF protein was detected in the $\mathrm{H}$ group. In contrast, hHGF was undetectable in the $\mathrm{C}$ and $\mathrm{E}$ groups (Figure 1,C and $D$ ). All these results showed the expression of rhHGF protein in the lung tissues after transfection, which indicated that the endotracheal approach was an efficient pathway for gene transfection of the lung.

\section{Impact of Adenovirus Coding With Human Hepatocyte Growth Factor Transfection on Vessel Density in Lung}

To evaluate the angiogenesis in lung after gene transfection, VIII factor, a specific marker for VECs, was examined in the lung tissues. Two weeks after rhHGF transfection, immunocytochemistry stain of VIII factor showed that the microvascular density in the lung tissues of the $\mathrm{H}$ group was $19.7 \pm 2.8 / \mathrm{mm}^{2}$, which was significantly higher than in the $\mathrm{C}$ group $\left(13.2 \pm 3.2 / \mathrm{mm}^{2}, P<.05\right)$ and $\mathrm{E}$ group $\left(14.8 \pm 2.7 / \mathrm{mm}^{2}, P<.05\right.$, Figure 2$)$. These results implied 

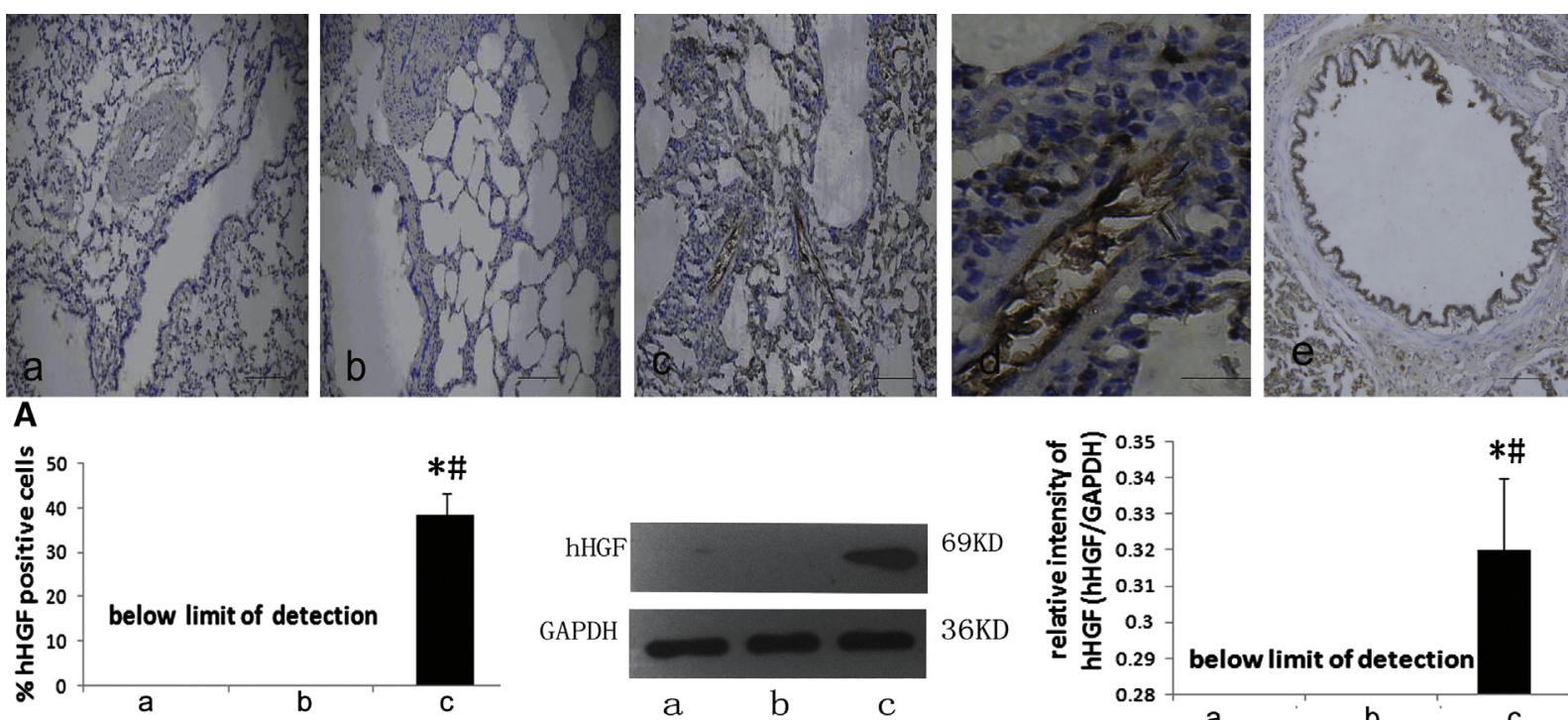

B
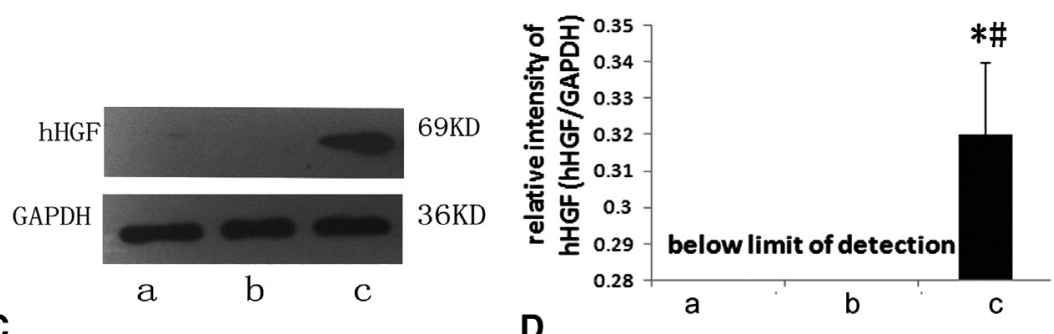

FIGURE 1. A, Immunohistochemistry examination of hHGF in lung tissues (n $=120$ slices per group). A- $a, \mathrm{C}$ group. A- $b, \mathrm{E}$ group. A- $c, \mathrm{H}$ group. A- $d$, Magnification of A-c. A-e, hHGF expression in the bronchial epithelium. In contrast to the $\mathrm{C}$ and $\mathrm{E}$ groups, positive signals were observed in the cytoplasm of VECs and epithelial cells in lung tissues of the H group. Bar $=100 \mu \mathrm{m}$. B, Semiquantitative analysis of the hHGF immunohistochemistry examination. $a, \mathrm{C}$ group. $b$, E group. $c, \mathrm{H}$ group. ${ }^{*} P<.05$ versus $\mathrm{C}$ group. $\# P<.05$ versus $\mathrm{E}$ group. $\mathrm{C}$, Western blot showed that no specific band in the $\mathrm{C}$ and $\mathrm{E}$ groups $(\mathrm{n}=12$ per group) and the band in the $\mathrm{H}$ group $(\mathrm{n}=12)$ were proved to be the hHGF after gene transfection. D, Relative intensity of hHGF in the 3 groups. $a$, C group. $b$, E group. $c, \mathrm{H}$ group. $* P<.05$ versus $\mathrm{C}$ group. $\# P<.05$ versus $\mathrm{E}$ group. $G A P D H$, Glyceraldehyde phosphate dehydrogenase; $h H G F$, human hepatocyte growth factor.

that the arteriolar density was increased in lung tissues after hHGF transfection in rabbits with PAH.

There were 3 types of acinar artery in the lung: muscular, partial muscular, and nonmuscular. The nonmuscular-type and partial muscular-type vessels were the main functional vessels; the latter especially plays an important role in the perfusion of lung tissues. The promotion of the partial muscular artery also was assayed using double-labeling immunofluorescence histochemistry. VECs were labeled with fluorescein isothiocyanate (VIII factor staining), and SMCs were labeled with rhodamine ( $\alpha$-smooth muscle actin antibody). Immunofluorescence analysis suggested that the density of partial muscular arteries in the $\mathrm{H}$ group was higher than in the $\mathrm{C}$ and $\mathrm{E}$ groups $\left(17.3 \pm 3.5 / \mathrm{mm}^{2}\right.$ vs $9.5 \pm 3.2 / \mathrm{mm}^{2}, P<.05$; and $17.3 \pm 3.5 / \mathrm{mm}^{2}$ vs $7.4 \pm 2.7 / \mathrm{mm}^{2}, P<.05$, respectively) (Figure 3 ). The increase in nonmuscular (VIII factor stain) and partial muscular arteries (double-labeling immunofluorescence) ensured efficient gas exchange and perfusion in the $\mathrm{H}$ group. These results showed that rhHGF transfection promoted functional angiogenesis in the lung tissue of PAH models.

\section{Morphology and Distribution of Pulmonary Arterioles}

To measure lung blood perfusion, pulmonary artery angiography was performed. In the $\mathrm{C}$ and $\mathrm{E}$ groups, the expansion of pulmonary trunk, sudden attenuation, or termination of pulmonary artery branches, which was called "residual root-like" changes, and decrease of remote branches of pulmonary artery were observed in the pulmonary artery angiography (Figure 4). In the $\mathrm{H}$ group, pulmonary hypertension images also were observed, but the changes in the pulmonary trunk were slight and the number of remote branches of the pulmonary artery obviously increased with the distribution in a network style. Prolonged contrast medium filling time in the pulmonary artery (including the termination branches) was detected in the C group ( $2376 \pm 748 \mathrm{~ms}$, $\mathrm{n}=12)$ and $\mathrm{E}$ group $(2197 \pm 581 \mathrm{~ms}, \mathrm{n}=12)$. The meglumine filling time in the $\mathrm{H}$ group $(\mathrm{n}=12)$ was shorter than in the $\mathrm{C}$ and $\mathrm{E}$ groups $(1579 \pm 542 \mathrm{~ms}$ vs $2376 \pm 748 \mathrm{~ms}$, $P<.05$ and $1579 \pm 542 \mathrm{~ms}$ vs $2197 \pm 581 \mathrm{~ms}, P<.05$, respectively).

\section{DISCUSSION}

The current study demonstrated that (1) the intratracheal transfection of the rhHGF induced the expression of hHGF in lung tissues of rabbits with PAH; (2) the transfection of rhHGF ameliorated pulmonary arterial pressure in animals with PAH induced by a shunt flow; and (3) the decrease in pulmonary arterial pressure and improvement in blood perfusion after rhHGF transfection may be due to the arteriolar angiogenesis in the lung.

A number of different viral and nonviral vector systems are in use to transfer genes to lung tissue. Each vector has 

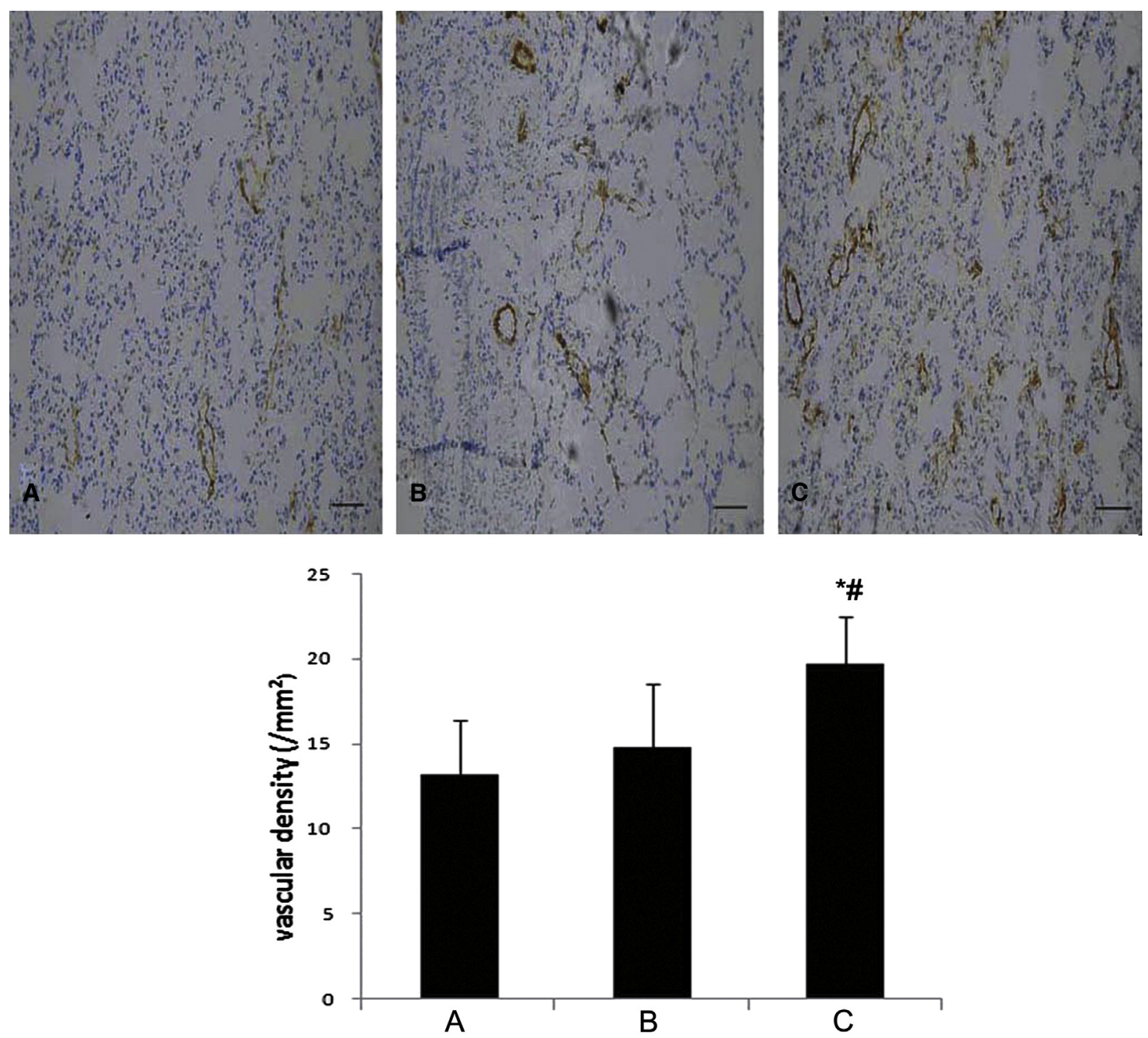

FIGURE 2. Immunohistochemistry examination for anti-VIII factor stain $(\mathrm{n}=120$ slices per group). $A$, C group. $B, \mathrm{E}$ group. $C, \mathrm{H}$ group. $B a r=100 \mu \mathrm{m}$. $* P<.05$ versus $\mathrm{C}$ group. $\# P<.05$ versus $\mathrm{E}$ group.

its advantages and disadvantages in DNA-carrying capacity. The replication-incompetent recombinant adenovirus was used in the current study because of its high-efficiency transduction in a wide variety of target cells and high expression of the delivery transgene. Furthermore, adenovirus is stable in vivo, permitting direct delivery of the gene to the lung parenchyma. ${ }^{20}$ According to the characteristics of adenovirus and the respiratory system, Ad-hHGF could be delivered through the endotracheal pathway but not via an invasive method, such as catheter insertion. ${ }^{9,12}$ Local and systemic inflammatory responses were the main disadvantage of adenovirus-mediated gene transfection. The preliminary study ${ }^{21}$ showed that unlike the intravenous method, the intratracheal pathway for gene transfer to lung confined the transient inflammation response in the respiratory tract rather than in the system. Moreover, with the use of green fluorescent protein as a report gene, our early study showed that there are few signals of green fluorescent protein in the heart and liver tissues via an intratracheal approach. ${ }^{21}$ After gene transfection, no symptoms of respiratory or other complications were detected in the animals. Systemic arterial pressure and heart rate were not influenced in the rabbits in the $\mathrm{E}$ and $\mathrm{H}$ groups. Furthermore, hHGF is highly expressed in bronchial epithelium, alveolar epithelium, and pulmonary VECs. Immunoblotting also confirmed that the expressed protein was hHGF. These results implied that intratracheal transfer of Ad-Null or Ad-hHGF was safe and targeted the respiratory system. Therefore, gene transfer to the pulmonary vascular bed via an intratracheal approach was an effective method for administering a viral vector in the treatment of pulmonary disease. In addition to the high efficiency and clear 

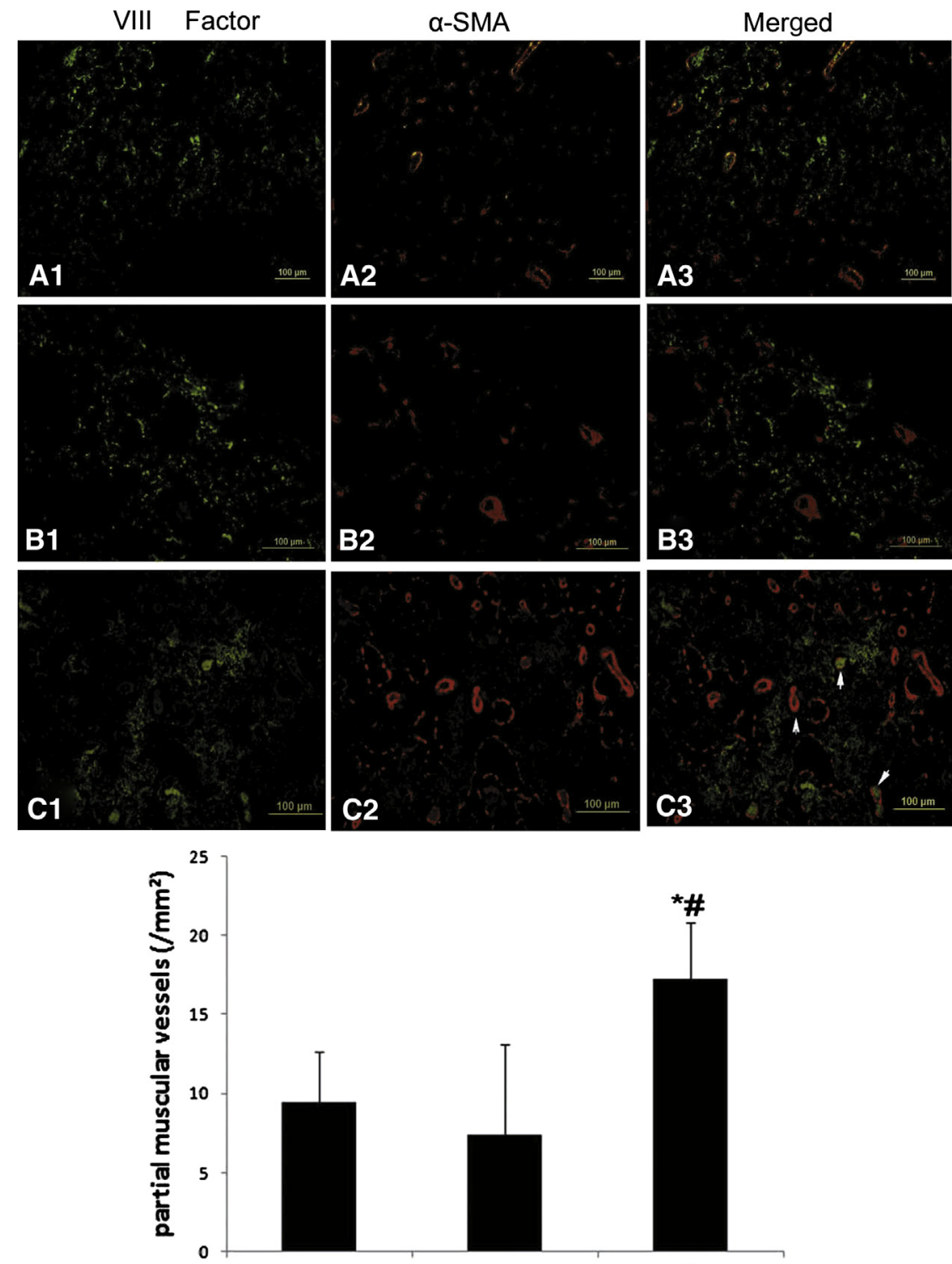

A

B

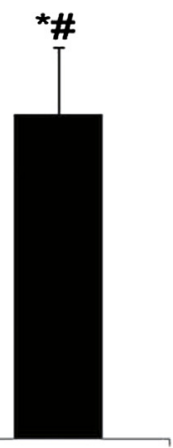

C

FIGURE 3. VIII factor antibody was labeled with fluorescein isothiocyanate (green), and $\alpha$-smooth muscle actin antibody was labeled with rhodamine (red). Arrows indicate the partial muscular arteries. A1-A3, C group. B1-B3, E group. C1-C3, H group. Bar $=100 \mu \mathrm{m}$. The partial muscular vessel density was analyzed ( $\mathrm{n}=120$ per group). $A, \mathrm{C}$ group. $B$, E group. $C, \mathrm{H}$ group. ${ }^{*} P<.05$ versus $\mathrm{C}$ group. $\# P<.05$ versus $\mathrm{E}$ group. $\alpha$-SMA, $\alpha$-smooth muscle actin.

targeting, gene transfer to lung with an intratracheal approach avoided the blood dilution and severe systemic inflammation caused by the vehicle.

In the vascular remodeling caused by PAH, pulmonary intra-acinar arteries are the key blood vessels for hemodynamic regulation. With transformation of the nonmuscular and partial muscular types into the muscular type, luminal stenosis and occlusion are the pathologic basis of PAH. ${ }^{22}$ The rhHGF transfection in the current study promoted angiogenesis in the lung tissues of PAH models, which was confirmed by immunohistochemistry. The partial muscular-type artery was the main vessel for controlling perfusion of the lung.
Immunofluorescence examination showed that the partial muscular-type arteries were significantly increased after hHGF transfection. Therapeutic angiogenesis promoted the collateral circulation and thus reduced the vascular resistance and improved the perfusion of the organ. This might have contributed to the decrease in pulmonary arterial pressure in the $\mathrm{H}$ group. Of note, although the hHGF transfection promoted the generation of partial muscular type arteries in the lung, it did not aggravate the original proliferation of SMCs. This phenomenon might be due to the antifibrotic character of HGF, which had been thoroughly proved. ${ }^{11,23}$ HGF promoted angiogenesis after transfection but also inhibited 

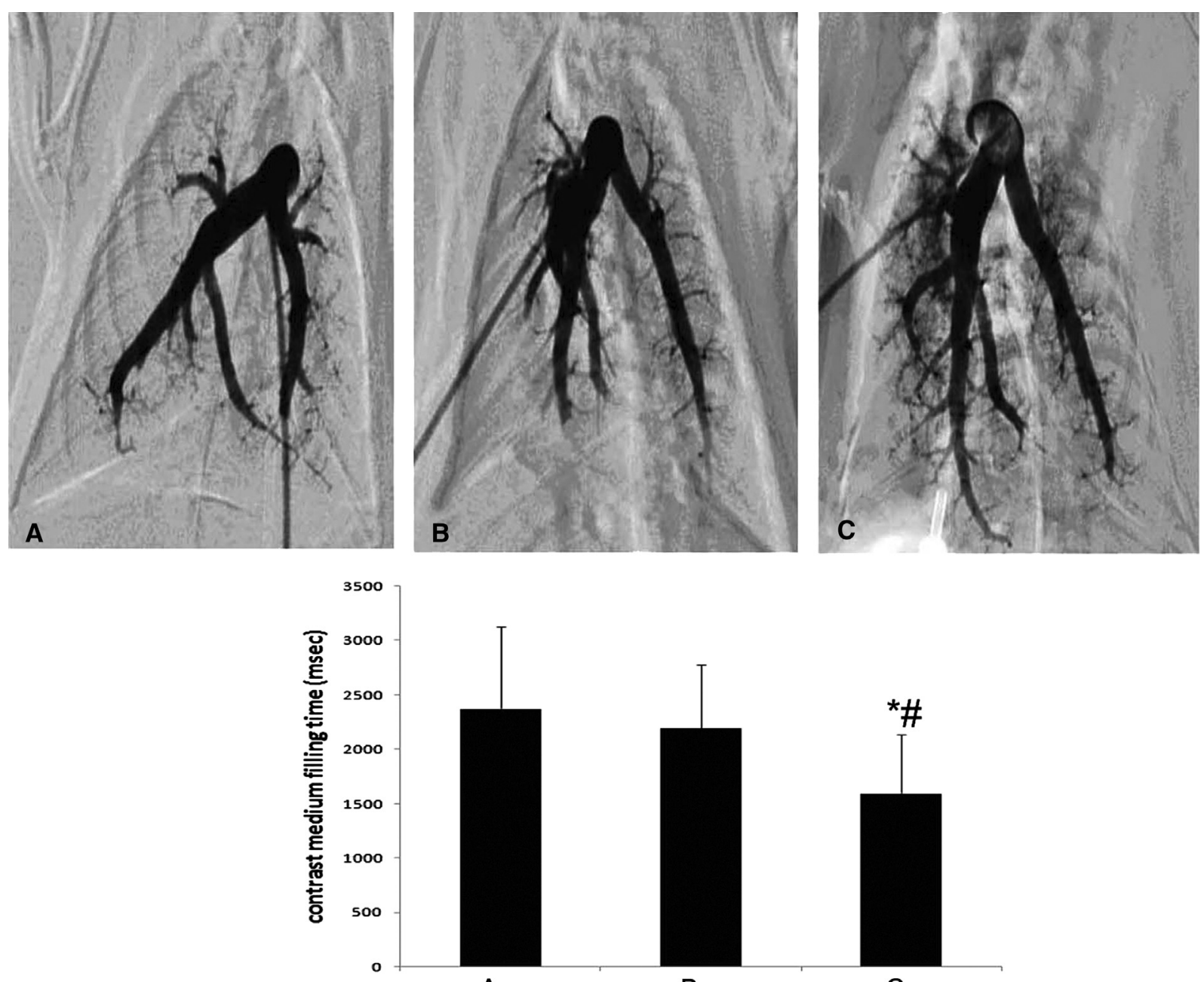

A

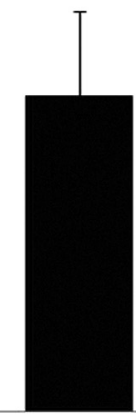

B

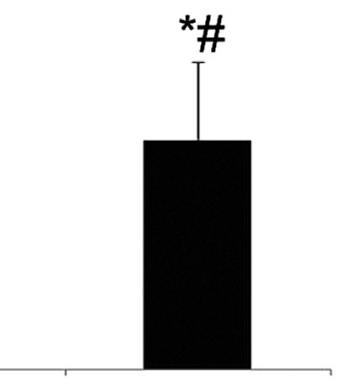

C

FIGURE 4. Pulmonary artery angiography under digital subtraction angiography. $A, \mathrm{C}$ group. $B, \mathrm{E}$ group. $C, \mathrm{H}$ group. The contrast filling time was calculated in the angiography ( $\mathrm{n}=12$ per group). ${ }^{*} P<.05$ versus $\mathrm{C}$ group. $\# P<.05$ versus $\mathrm{E}$ group.

the exacerbation of the primary disorder through its antifibrotic mechanisms, such as attenuation of collagen accumulation. ${ }^{11}$ The pulmonary angiography results correlated well with the results of immunocytochemistry and immunofluorescence stain for vascular density. Pulmonary angiography showed that the meglumine filling time was prolonged in the $\mathrm{C}$ and $\mathrm{E}$ groups, which may have been caused by the partial occlusion of the arterioles in the rabbits with PAH. In the $\mathrm{H}$ group, the enlargement of the pulmonary vascular bed decreased the resistance of the contrast medium perfusion to a certain degree. Thus, we speculated that Ad-hHGF transfection effectively reduced the pulmonary artery pressure via the angiogenesis in the lung. This result was partially confirmed in previous studies. ${ }^{12,16}$

Because of the heterogeneity of the vehicle and exogenous gene, the innate immunoreaction was activated, which resulted in the production of neutralizing antibodies by the host, preventing the productive readministration. A previous study by Wang and colleagues ${ }^{16}$ indicated that the repeated application had an inefficient gene delivery and that the hHGF expression was gradually attenuated and eliminated after 4 weeks in the adenovirus-mediated gene transfer. It was speculated that after the first transfection, a specific antibody had been produced to avoid the side effects caused by the prolonged exogenous gene expression. Therefore, short-term and stepwise expression of the adenovirus-mediated hHGF gene guaranteed the safety of the treatment, especially in PAH. Because the recombinant genes that can independently express a therapeutic RNA or protein are extraordinarily large and polar molecules $(10,000$ times larger than traditional pharmaceutical agents ${ }^{24}$ ), a single transfection achieved a satisfying result. However, the long-term therapeutic effect of hHGF and the survival analysis in PAH deserve further investigation.

\section{Study Limitations}

A limitation of this study was the absence of data on the V/Q ratio or the blood gas analysis after the gene 
transfection. In addition, the measurement of right ventricular function should be performed to better delineate the PAH improvement. The changes of the relative factors that were important in the development of PAH (eg, endothelial nitric oxide synthase) are being investigated to explore the underlying mechanisms induced by the hHGF gene transfection.

\section{CONCLUSIONS}

Collectively, rhHGF transfection via an endotracheal approach in the PAH rabbit models induced by shunt flow decreases pulmonary artery pressure by promoting angiogenesis in the lung. The current study may provide new ideas for the therapy of PAH induced by shunt flow, which is significant for advanced congenital cardiac disease.

The authors thank academician Wu Zuze for the donation of recombinant adenovirus vector and the technologic guidance.

\section{References}

1. Roos-Hesselink JW, Meijboom FJ, Spitaels SE, Van Domburg R, Van Rijen EH, Utens EM, et al. Outcome of patients after surgical closure of ventricular septal defect at young age: longitudinal follow-up of 22-34 years. Eur Heart J. 2004;25: 1057-62.

2. Bui MT, Grollmus O, Ly M, Mandache A, Fadel E, Decante B, et al. Surgical palliation of primary pulmonary arterial hypertension by an unidirectional valved Potts anastomosis in an animal model. J Thorac Cardiovasc Surg. 2011;142:1223-8.

3. Galie N, Manes A, Palazzini M, Negro L, Marinelli A, Gambetti S, et al. Management of pulmonary arterial hypertension associated with congenital systemic-topulmonary shunts and Eisenmenger's syndrome. Drugs. 2008;68:1049-66.

4. Cristofaro B, Stone OA, Caporali A, Dawbarn D, Ieronimakis N, Reyes M, et al. Neurotrophin-3 is a novel angiogenic factor capable of therapeutic neovascularization in a mouse model of limb ischemia. Arterioscler Thromb Vasc Biol. 2010;30:1143-50

5. Oostendorp M, Douma K, Wagenaar A, Slenter JM, Hackeng TM, van Zandvoort MA, et al. Molecular magnetic resonance imaging of myocardial angiogenesis after acute myocardial infarction. Circulation. 2010;121:775-83.

6. Van Belle E, Witzenbichler B, Chen D, Silver M, Chang L, Schwall R, et al. Potentiated angiogenic effect of scatter factor/hepatocyte growth factor via induction of vascular endothelial growth factor: the case for paracrine amplification of angiogenesis. Circulation. 1998;97:381-90.

7. Morishita R, Nakamura S, Hayashi S, Taniyama Y, Moriguchi A, Nagano T, et al. Therapeutic angiogenesis induced by human recombinant hepatocyte growth factor in rabbit hind limb ischemia model as cytokine supplement therapy. $\mathrm{Hy}$ pertension. 1999;33:1379-84.

8. Shirakawa Y, Sawa Y, Takewa Y, Tatsumi E, Kaneda Y, Taenaka Y, et al. Gene transfection with human hepatocyte growth factor complementary DNA plasmids attenuates cardiac remodeling after acute myocardial infarction in goat hearts implanted with ventricular assist devices. J Thorac Cardiovasc Surg. 2005; 130:624-32.

9. Ono M, Sawa Y, Mizuno S, Fukushima N, Ichikawa H, Bessho K, et al. Hepatocyte growth factor suppresses vascular medial hyperplasia and matrix accumulation in advanced pulmonary hypertension of rats. Circulation. 2004;110: 2896-902.

10. Azuma J, Taniyama Y, Takeya Y, Iekushi K, Aoki M, Dosaka N, et al. Angiogenic and antifibrotic actions of hepatocyte growth factor improve cardiac dysfunction in porcine ischemic cardiomyopathy. Gene Ther. 2006;13:1206-13.

11. Dohi M, Hasegawa T, Yamamoto K, Marshall BC. Hepatocyte growth factor attenuates collagen accumulation in a murine model of pulmonary fibrosis. Am J Respir Crit Care Med. 2000;162:2302-7.

12. Hiramine K, Sata N, Ido A, Kamimura R, Setoyama K, Arai K, et al. Hepatocyte growth factor improves the survival of rats with pulmonary arterial hypertension via the amelioration of pulmonary hemodynamics. Int J Mol Med. 2011;27: 497-502.

13. Wang W, Liu R, Cao G, Zhang F, Zhang Y, Zhang Z, et al. A reliable rabbit mode for hyperkinetic pulmonary hypertension. J Thorac Cardiovasc Surg. 2010;140: 395-9.

14. Ha X, Yuan B, Li Y, Lao M, Wu Z. Gene therapy for pathological scar with hepatocyte growth factor mediated by recombinant adenovirus vector. Sci China C Life Sci. 2003;46:320-7.

15. Champion HC, Bivalacqua TJ, D'Souza FM, Orteiz LA, Jeter JR, Toyoda K, et al. Gene transfer of endothelial nitric oxide synthase to the lung of the mouse in vivo. Effect on agonist-induced and flow mediated vascular responses. Circ Res. 1999; 84:1422-32

16. Wang W, Wu S, Zhang Z, Zhang Y. In vivo transfection of hepatocyte growth factor gene induces pulmonary angiogenesis in the rabbit with hyperkinetic pulmonary hypertension. Zhonghua Xin Xue Guan Bing Za Zhi. 2008;36:1110-4.

17. Louzier V, Eddahibi S, Raffestin B, Deprez I, Adam M, Levame M, et al. Adenovirus-mediated atrial natriuretic protein expression in the lung protects rats from hypoxia-induced pulmonary hypertension. Hum Gene Ther. 2001;12: 503-13.

18. Nagaya N, Yokoyama C, Kyotani S, Shimonishi M, Morishita R, Uematsu M, et al. Gene transfer of human prostacyclin synthase ameliorates monocrotalineinduced pulmonary hypertension in rats. Circulation. 2000;102:2005-10.

19. Liu K, Liu R, Cao G, Sun H, Wang X, Wu S. Adipose-derived stromal cell autologous transplantation ameliorates pulmonary arterial hypertension induced by shunt flow in rat models. Stem Cell Dev. 2011;20:1001-10.

20. Steven MA, Rainer W, Jonathan BZ. Gene therapy for lung disease: hype or hope? Ann Intern Med. 2000;132:649-60.

21. Wang W, Wu S, Zhang Z, Zhang Y. Efficiency and toxicity assess of the adenovirus mediated gene transfection through intratracheal and intravenous approach into lung. Chin J Pathophysiol. 2008;24:2493-6.

22. Taniyama Y, Morishita R, Hiraoka K, Aoki M, Nakagami H, Yamasaki K, et al Therapeutic angiogenesis induced by human hepatocyte growth factor gene in rat diabetic hind limb ischemia model: molecular mechanisms of delayed angiogenesis in diabetes. Circulation. 2001;104:2344-50.

23. Mizuno S, Matsumoto K, Li MY, Nakamura T. HGF reduces advancing lung fibrosis in mice: a potential role for MMP-dependent myofibroblast apoptosis. FASEB J. 2005;19:580-2.

24. Wilson JM. Adenoviruses as gene-delivery vehicles. N Engl J Med. 1996;334 1185-7. 